\title{
A LEITURA MEDIADA COMO ESTRATÉGIA DE CUIDADO LÚDICO: CONTRIBUIÇÃO AO CAMPO DA ENFERMAGEM FUNDAMENTAL
}

\author{
The mediate reading as a ludic care strategy: Contribution to the \\ basic nursing area
}

\section{La lectura mediada como atención lúdica: contribución al campo de la enfermería básica}

\begin{abstract}
RESUMO
0 objeto é a leitura mediada à criança hospitalizada como estratégia lúdica. Os objetivos são: Identificar os sentidos atribuídos pelos sujeitos às ações de mediação de leitura; caracterizar suas contribuições às crianças hospitalizadas; e discutir a leitura mediada como estratégia expressiva/lúdica de cuidado fundamental. Pesquisa qualitativa e descritiva realizada com 10 crianças hospitalizadas; 10 acompanhantes; 7 mediadores de leitura; e 10 membros da equipe de enfermagem. Evidenciaram-se os benefícios da leitura no bem-estar das crianças e seus acompanhantes, favorecendo o trabalho da equipe de saúde. Para os profissionais e mediadores, a leitura mediada é uma estratégia de humanização do cuidado que diminui a sobrecarga psíquica e proporciona conforto emocional à criança, amenizando seu sofrimento. Concluiu-se que aliar o ludismo ao cuidado vem ao encontro dos princípios da teoria do cuidado humano e, também, do Projeto Humaniza SUS, cujas estratégias de acolhimento do cliente ganham vulto.
\end{abstract}

PALAVRAS-CHAVE: Cuidados de Enfermagem. Saúde da Criança. Humanização da Assistência.

\begin{abstract}
The purpose is the mediated reading to hospitalized child as "ludic" strategy. The objectives are: Identify the meanings of reading mediation actions attributed by the subjects; characterize their contributions to hospitalized children, and discuss the mediated reading as expressive / "ludic" strategy of basic care. It is a descriptive and qualitative study conducted with 10 hospitalized children and their 10 escorts; 07 reading mediators, and 10 nursing team's members. The benefits of reading were evidenced on children and their escort's wellbeing which promote the health team's work. For the professionals and mediators, the mediated reading is a humanization care strategy that reduce psychic surcharge and provides emotional comfort to the children, softening their suffering. It concluded that combining "ludism" and care is in line with the principles of the theory of human care and also the project called Humaniza SUS, whose host strategies of customer are valued.
\end{abstract}

Keywords: Nursing care. Child health. Humanization of Assistance.

\section{Resumen}

El objeto es la lectura guiada como estrategia lúdica para los niños hospitalizados. Los objetivos son: Identificar los sentidos que les atribuyen los sujetos a las acciones de mediación de lectura; caracterizar la contribución hecha a los niños hospitalizados; y discutir la lectura guiada como una estrategia expresiva/lúdica de cuidado fundamental. Se trata de una investigación cualitativa y descriptiva realizada con 10 niños hospitalizados; 10 acompañantes; 07 mediadores de lectura; y 10 miembros del equipo de enfermería. Es evidente los beneficios de la lectura en el bien-estar de los niños y sus acompañantes, favoreciendo el trabajo del equipo de salud. Para los profesionales y mediadores, la lectura guiada es una estrategia de humanización del cuidado que disminuye la sobrecarga psíquica y proporciona conforto emocional al niño, amenizando su sufrimiento. Se concluyó que aliar actividades lúdicas con cuidados y atención se concretizan como los principios de la teoría del cuidado humano y, también, del Proyecto Humaniza SUS, cuyas estrategias de acoger al paciente están ganando cada dia más importancia.

Palabras claves: Atención de Enfermería. Salud del niño. Humanización da Asistencia .

\footnotetext{
Aluna do $8^{\circ}$. Período do curso de graduação em enfermagem da Escola de Enfermagem Anna Nery (EEAN) da Universidade Federal do Rio de Janeiro (UFRJ). Bolsista do PIBICICNPQ. Membro da Diretoria do Núcleo de Pesquisa de Fundamentos do Cuidado de Enfermagem (Nuclearte). Brasil. E-mail: little rodrigues@yahoo.com.br, ${ }^{2}$ Aluna do 8. Período do curso de graduação em enfermagem da Escola de Enfermagem Anna Nery (EEAN) da Universidade Federal do Rio de Janeiro (UFRJ). Bolsista do PIBICICNPQ. Membro da Diretoria do Núcleo de Pesquisa de Fundamentos do Cuidado de Enfermagem (Nuclearte). Brasil. E-mail: priscillabroca@ig.com.br, ${ }^{3}$ Doutora em Enfermagem. Coordenadora Geral de Pós-Graduação e Pesquisa da EEAN, da UFRJ. Professora Titular do Departamento de Enfermagem Fundamental (DEF) da EEAN/UFRJ. Membro da Diretoria do Nuclearte. Brasil. E-mail: marciadeaf@ibest.com.br
} 


\section{INTRODUCÃO}

O cuidado prestado por meio das ações de enfermagem se realiza na medida em que oferece conforto e mantém a dignidade humana, o que propicia às pessoas o melhor enfrentamento do sofrimento e da dor causados pela doença, tendo o sentido de promover e resgatar a saúde.

Neste estudo, a enfermagem é entendida como uma ciência fundamentada nas práticas de cuidar do ser humano, valorizando suas experiências e abrangendo tanto seu estado de saúde como o de doença. Neste sentido, a enfermagem aplica a abordagem humanística no ato de cuidar, caracterizando-o como cuidado humano, que se expressa pela interação entre os sujeitos (aquele que cuida e aquele que é cuidado).

0 Projeto HumanizaSUS entende humanização por valorização da autonomia e protagonismo de todos os sujeitos envolvidos no processo de saúde, estabelecendo corresponsabilidade, vínculos solidários e participação coletiva, - que contribui para a identificação das necessidades coletivas, sociais e subjetivas de saúde, promovendo a troca e construção de saberes entre os sujeitos.

Estes são conceitos e pressupostos gerais de cuidado que se aplicam a todos os clientes, sem distinguir marcadores como sexo, idade e condições de vida e saúde. Porém, no que se refere às crianças, deve-se considerar sua especificidade, uma vez que, nesta fase da vida, o ser tem maior dificuldade em lidar com o desconhecido e de enfrentar seus medos, tornandose inseguro e ansioso. Mesmo hospitalizada, a criança não perde suas características infantis, como a vontade de brincar e receber afeto.

Nesse sentido, o carinho, o contato físico e a percepção, que são estímulos fundamentais para a saúde das crianças de todas as idades, contribuem para a manutenção do equilíbrio físico e emocional tanto quanto os alimentos e os remédios. A falta destes cuidados pode até impedir a recuperação da criança, mesmo com todo o tratamento especializado oferecido. ${ }^{2}$

A leitura de textos literários à criança hospitalizada pode exercer função terapêutica (biblioterapia), proporcionando a pacificação das emoções pela catarse, operando no leitor e no ouvinte o efeito de placidez, pois a literatura, além de possuir a virtude de ser sedativa e curativa, pode estimular as crianças a se comunicarem, perderem a timidez, exporem seus problemas emocionais e físicos. ${ }^{3}$

Neste sentido, destaca-se o Projeto Biblioteca Viva em Hospitais (PBVH), uma estratégia de biblioterapia implantada em hospitais pediátricos, atendendo à criança hospitalizada e em ambulatório, com intuito de melhorar a relação entre as crianças e os profissionais da área de saúde. 0 projeto utiliza a estratégia de mediação para efetivar a leitura terapêutica, ou seja, o leitor (mediador) serve de intermediário entre o livro e o ouvinte.

Assim, o mediador aborda a criança em momentos oportunos, mostrando os livros para que possa escolher as histórias, optando por ouvir a leitura, folheá-los, tocá-los ou simplesmente brincar com eles. A leitura dirigida, como ação de humanização do atendimento à criança hospitalizada, pode ser caracterizada como um cuidado expressivo, que considera as particularidades e individualidade do outro, e ainda se expressa na emoção, tornando o cuidado humano e valorizando a presença do sujeito. ${ }^{4}$

Desta maneira, o PBVH foi implantado na cidade do Rio de Janeiro em instituições de saúde, destacando-se as seguintes: Instituto de Puericultura e Pediatria Martagão Gesteira (IPPMG), Instituto Fernandes Figueira, Hospital Geral de Bonsucesso e Hospital Municipal Jesus, Hospital Carlos Chagas. Além disso, foi implantado efetivamente também em outras cidades do Brasil.

Aarte de cuidar em enfermagem busca diversas estratégias para o cuidado à criança; assim, o lúdico pode ser usado como uma qualidade que efetiva o cuidado humano de enfermagem, pois amplia a visão deste cuidado para além da observação puramente fisiopatológica, envolvendo manifestações de afeto à criança que está hospitalizada. ${ }^{5}$ Destaca-se que a biblioterapia se expressa como uma alternativa lúdica que possibilita aumentar as expectativas e o conhecimento da criança em relação à hospitalização.

A problemática desta pesquisa é que, apesar de toda esta gama de contribuições possíveis que a leitura mediada possa trazer para o cuidado fundamental à criança hospitalizada, ao longo do desenvolvimento do projeto, não se vem observando um engajamento da equipe de enfermagem nas suas ações. Destaca-se, ainda, que não temos na área da saúde, no âmbito da Universidade Federal do Rio de Janeiro (UFRJ), trabalhos específicos que busquem discutir a importância da estratégia lúdica enquanto cuidado fundamental. Além disso, variáveis que descrevam e expliquem a percepção dos sujeitos em relação às ações relacionadas à humanização devem ser valorizadas como objeto de avaliação, de forma a qualificar a assistência à luz do HumanizaSUS. ${ }^{1}$

Assim, delimita-se o objeto desta investigação: a leitura mediada à criança hospitalizada como estratégia lúdica.

Os objetivos são: Identificar os sentidos atribuídos pelos sujeitos às ações de mediação de leitura realizadas junto à criança hospitalizada; caracterizar as contribuições da leitura mediada no âmbito do tratamento e recuperação da criança hospitalizada, a partir da experiência dos sujeitos envolvidos na ação; analisar as possibilidades de integração da leitura mediada no cotidiano do cuidado à criança hospitalizada; discutir a leitura mediada como estratégia expressiva/lúdica de cuidado fundamental. Como contribuições, destacam-se as práticas e as teóricas. Quanto às primeiras, espera-se dar visibilidade às ações realizadas no âmbito do PBVH e oferecer subsídios para se qualificar ainda mais o cuidado prestado à criança hospitalizada; quanto à segunda, espera-se contribuir para as discussões sobre o lúdico no campo dos fundamentos do cuidado em enfermagem. 


\section{METODOLOGIA}

Esta pesquisa é de natureza qualitativa-descritiva, cujos dados foram produzidos a partir da aplicação de três técnicas: A livre associação de ideias (LAl) com o fornecimento de palavras-indutoras para exploração dos sentidos dos sujeitos sobre o objeto de estudo; a entrevista semiestruturada, baseada em roteiro com questões abertas que abarcaram os dados sobre a identificação dos sujeitos; e a observação participante da dinâmica da enfermaria e dos sujeitos quando da realização da leitura mediada. Cumpre esclarecer que o roteiro de entrevista aplicado junto às crianças utilizou como recurso os símbolos do emoticons para que elas pudessem melhor expressar os conteúdos sobre seus sentimentos de indiferença, alegria e tristeza.

As entrevistas foram registradas eletronicamente, e as observações compuseram um diário de campo, com o amparo teórico da descrição densa. ${ }^{6}$ Antes de serem aplicados, todos os instrumentos foram testados. Ao conteúdo foram aplicadas as técnicas de análise temática. ${ }^{7}$

Os sujeitos foram 10 crianças hospitalizadas, de ambos os sexos, internadas nas enfermarias de escolares, que participaram das ações de leitura mediada no decorrer do processo de internação; 10 acompanhantes; 7 mediadores de leitura engajados efetivamente no Projeto; e 10 membros da equipe de enfermagem que tiveram a experiência de receber os mediadores de leitura no decorrer dos seus plantões. Desta forma, totalizam-se 37 sujeitos.

O local é a Unidade de Pacientes Internados do IPPMG/ UFRJ. Esta Unidade possui 7 enfermarias, com 8 leitos cada. A equipe de enfermagem é composta por 1 enfermeiro diarista por enfermaria, 2 enfermeiros plantonistas e uma média de 8 a 9 técnicos e auxiliares de enfermagem por plantão. As enfermarias são separadas conforme a idade das crianças, com exceção das enfermarias de Cirurgia Pediátrica e de Hematologia. 0 tempo de internação das crianças varia de acordo com as enfermarias, sendo a média de 8,38 dias. ${ }^{8}$

O disposto na Resolução n ${ }^{0}$ 196/96 do Conselho Nacional de Saúde foi atendido e o Projeto foi aprovado no Comitê de Ética em pesquisa do IPPMG/UFRJ, conforme o protocolo $\mathrm{n}^{0}$. 03/07. A identificação dos sujeitos foi feita por códigos alfanuméricos, dos quais a letra $C, A, M$ e $P$ significam, respectivamente, criança, acompanhante, mediador de leitura, profissional; $\mathrm{Fe}$ M significam, respectivamente, os sexos feminino e masculino; os números seguem a ordem de ocorrência das entrevistas.

\section{RESULTADO E DISCUSSÃO}

A análise de conteúdo dos depoimentos das crianças e acompanhantes delineou categorias temáticas que evidenciaram os atributos e os benefícios do cuidado. Quanto aos atributos, foi possível classificar os humanos, ou seja, aqueles relativos aos agentes e sujeitos, como a atenção e o carinho dedicado à criança durante a mediação; e os relacionados à ação em si, que mostrou a expressão lúdica da leitura de histórias às crianças.

Por meio do lúdico pode-se fazer fluir a criatividade e sensibilidade humanas de diferentes modos e formas. Quando aplicado ao cuidado, o ludismo coloca-se como uma "linha de fuga" às normas instituídas pelo hospital. ${ }^{5}$ Pela sua associação à arte de cuidar, o lúdico facilita as manifestações de carinho e afeto, contribuindo para a qualidade da relação humana tão necessária à efetivação do cuidado de enfermagem.

Em se tratando do cuidado à criança, a interação com o profissional torna-se fundamental, além do que pelo estágio de seu desenvolvimento, ela não deve se afastar da experiência de brincar, que integra o universo infantil. Nesse sentido, a leitura mediada emerge como uma estratégica de cuidar lúdico que pode ser aplicada pela enfermagem no cuidado à criança, no sentido de ajudá-la na adaptação à sua realidade.

As crianças hospitalizadas, ao serem questionadas sobre se havia alguma coisa no hospital de que elas gostavam, responderam positivamente exemplificando com: a escola, recreação, pintura, leituras e "Doutores da Alegria". As justificativas por tais indicações foram:

Porque não fico pensando besteira, me distraio (CF110 anos); Porque é uma forma de distração e é legal (CF3-12 anos); porque distrai (CM4 - 13 anos); Porque eu gosto de ler (CF5 - 9 anos).

A leitura dirigida, enquanto estratégia lúdica, atua como um catalisador de qualquer adversidade, inclusive a internação, trazendo bem-estar para a criança e seu acompanhante, o que favorece o trabalho da equipe de saúde. Assim, o ludismo potencializa a dimensão fraternal do cuidar, estimulando 0 autoconhecimento e o desenvolvimento emocional, bem como mudanças de comportamento do sujeito favorecidas pela retomada do cuidado. ${ }^{9}$

Estas afirmações respaldam a discussão no que se refere aos benefícios do cuidado lúdico. Tais benefícios abrangem a promoção da interação entre as pessoas, a integração ao meio, a otimização da participação da criança no processo de tratamento; o incentivo/contribuição com o processo de aprendizagem; estímulo à autonomia e criatividade da criança; e promoção de bem-estar geral (principalmente no que compete aos aspectos psíquicos relativos ao humor). Alguns depoimentos servem de exemplo para mostrar tais categorias de benefícios:

Acho muito bom e importante, anima bastante a criança a tentar a recuperação, porque ela fica mais animada, mais um companheirismo, tipo uma reunião de amigos dos colegas dela da escola. $A$ criança fica mais participativa. [o trabalho] Deve continuar, porque ajuda a criança a aumentar o interesse pela leitura (AM2, 37 anos); Acholegale 
importante, porque estimula as crianças que estão tristes e desperta sua criatividade (AF5, 19 anos); Acho bom porque a criança fica bem, feliz, mais animada e se interessa pela leitura, tem dia que a criança está triste e, quando começa a ouvir as histórias, ela fica animada. É uma forma de distração" (AF1, 29 anos); Acho bom. Gosto desse interesse pela leitura (AF3 - 39 anos).

Gostei. Porque conheci pessoas novas, e eles se preocupam comigo (CF3, 12 anos). Jáouvi histórias. Gosto de ouvir história porque eles (os mediadores) são legais e me deixam escolher os livros (CFI, 5 anos); "[Fico] feliz, porque rio das histórias (CM4, 13 anos).

A mediação de leitura atua beneficamente na promoção do resgate da alegria das crianças, quando se compara o antes, 0 durante e o depois das leituras, e também reverte no bemestar de seu acompanhante, na maioria das vezes a mãe da criança.

A leitura dirigida torna oportunas a construção e reconstrução das relações interpessoais, tão ricas nos processos humanos de convivência, principalmente entre a criança hospitalizada e o profissional de enfermagem, que realiza a parte significativa dos cuidados diretos. Além disso, proporciona melhor relação da criança com ambiente hospitalar. Desta forma, cria condições que possibilitam uma transcendência do cuidado técnico, que embora sejam indispensáveis na promoção e manutenção da saúde, tendem a afastar os profissionais da verdadeira essência da enfermagem: o cuidado ao ser humano. ${ }^{4}$

O processo de internação afasta as crianças das condições que contribuem para o seu processo educativo de ensinoaprendizagem, autonomia e criatividade. Desta maneira, a leitura mediada age de modo a estimular o desenvolvimento intelectual da criança hospitalizada, trazendo experiências que possibilitem seu aprendizado e criatividade, pois permite que ela manifeste sua visão lúdica do mundo. Além disso, proporciona um melhor diálogo com o profissional, estabelecendo uma relação harmoniosa entre eles.

O processo de internação afasta a criança de seu mundo cotidiano, gerando situações de insegurança para enfrentar o medo que sente da internação; assim, o ato de cuidar da criança hospitalizada se difere à medida que deve proporcionar também conforto emocional. A criança necessita de cuidados que contribuam para que a hospitalização interfira minimamente na sua recuperação física e emocional, pois não espera situações agradáveis vindas deste processo.

Os resultados apontam que os únicos momentos em que as crianças aceitam melhor o processo de internação são aqueles em que: ouvem estórias, participam da recreação, e quando os "Doutores da alegria" estão presentes no hospital. Como muitas crianças não podem frequentar a recreação, por conta de fatores como idade e tratamento, a leitura mediada no leito acaba sendo uma importante estratégia para contornar essa condição, trazendo momentos de alegria e distração para a criança.

Os acompanhantes entendem que o cuidado à criança hospitalizada deve valorizar o que eles denominam de "estado psicológico". Assim, aprovam o Projeto Biblioteca Viva e percebem que a leitura mediada tem grande valor e ajuda no tratamento. A maioria dos entrevistados não identifica interferência da leitura nos cuidados de enfermagem.

A análise de conteúdo dos mediadores e equipe de enfermagem delineou categorias temáticas que abrangeram os sentidos atribuídos à leitura mediada; e o comportamento da criança em relação à leitura mediada: os efeitos para as crianças e acompanhantes.

Os profissionais e mediadores entendem a leitura mediada como uma estratégia de humanização do cuidado que diminui a sobrecarga psíquica e proporcionam um conforto emocional da criança no decorrer do processo de hospitalização, pois esta ameniza o sofrimento e promove seu bem-estar. No depoimento de PF6, uma exceção aos demais, não se observa a valorização da leitura mediada no âmbito das ações de cuidar, embora nenhum dos depoimentos atribua, necessariamente, a responsabilidade da realização da leitura a alguém espećfico.

A leitura tem um papel de amenizar, dar conforto psíquico e emocional a criança para melhor aceitar o tratamento e a internação, porque, quando se está internado, qualquer coisa que ajude ao nosso estado de espirito é importante e válido para recuperação(PF3); [Éuma] forma de humanização e de beneficio para sua recuperação (PF4); Nós não temos a menor condição de, no momento da assistência, fazer esse trabalho, a equipe de trabalho aqui não comporta isso, então pra mim tem que haver um grupo destinado a isso (...). Por serisso, eu vejo uma coisa jábem delimitada (PF6).

Um dos aspectos que se aliaram aos resultados encontrados noos depoimentos das crianças e acompanhantes foi que os profissionais e mediadores reconhecem que a mediação de leitura interfere no humor das crianças, auxiliando em seu processo de adaptação, pois a comparação entre os estados que elas apresentam antes, durante e depois da mediação de leitura demonstra que esta atua beneficamente na promoção da alegria das crianças.

As crianças ficam ansiosas para saber quem vaiser a primeira. Edurante elas ficam compenetradas, mexendo nos livros e rindo. Edepois ficam sempre pedindo mais ou até acompanham o mediador quando ele vai contar para outra criança (PF3); No momento da leitura elas prestam muita atenção, depois elas ficam alegres. Antes estão meio 
desanimadas (PM5); Tem algumas crianças que, depois que você acaba de ler a história, aí elas pedem: 'Agora sou eu que vou contar a história pra você. 'Aí elas pegam o livro e começam a contara história (MF4).

Os benefícios que a leitura mediada traz emergem do cuidado que esta ação tem pelas particularidades da criança em tratamento e com sua família, e também da equipe de enfermagem. Tais efeitos são de várias ordens: psicológicos (estados de humor e comportamento), sociológicos (interação, participação) e pedagógicos (ensino-aprendizagem).

É importante ressaltar que tais benefícios são frutos da observação diária dos profissionais, mediadores e também dos acompanhantes ao comportamento das crianças que participam das leituras mediadas. Logo, são efeitos que efetivamente ocorrem e são identificados por aqueles que convivem com as mesmas no seu cotidiano da internação e, por isso, identificam a ocorrência de tais resultados.

Nota-se que emergem evidências de tais benefícios ao passo que os mesmos podem ser caracterizados e associados a determinadas ações e reações das crianças.

\section{Acho que é um sinal de que o projeto funciona, por causa da alegria vista durante as leituras. Interação, participação na escolha das histórias (MM1); de se desligar do ambiente hospitalar, onde dessa forma melhora a estadia da criança no hospital(MF2). 0 humor da criança muda para melhor, pois elas ficam mais calmas e interagem mais com o tratamento (PF1). É uma forma positiva para o tratamento delas, elas ficam mais receptivas; não veem o profissional apenas como aquele que causa dor, começa a ver que naquele ambiente não tem só dor, tem alguma coisa a mais, o mundo doloroso que éo hospital fica mais saudável (PF9).}

Assim, toda intervenção no ambiente hospitalar que contribua para a qualificação do cuidado à criança, na busca de uma melhor aceitação do processo de internação e ajuda ativa no tratamento deve ser valorizada no âmbito da assistência hospitalar.

Para os acompanhantes, os efeitos apareceram em duas ordens distintas: um trata do estado de humor, comportamento e lazer, e o outro diz respeito à necessidade que os acompanhantes têm de se distanciar, por um momento, da enfermaria, o que é favorecido pela leitura mediada uma vez que a criança estará em uma situação lúdica, o que tranquiliza os acompanhantes para tal afastamento.

Éomomento que elas veem que a criança estábem e alegre e fica tranquila em sair para fazer algo (MM1). Elas se divertem junto com as histórias, pedem livros para ler, e alguns aproveitam para sair, pois sabe que naquele momento a criança vai ficar bem (MF2). Às vezes parece que a gente está mediando pra criança e pra mãe, porque ela fica encantada também (MF4).

Os profissionais também se beneficiam da leitura mediada no que tange a melhora do humor, visto que eles usufruem da alegria e descontração de uma boa história infantil. Ainda mais, a leitura contribui para a sua interação com a criança, favorecendo a realização do serviço.

De um modo geral, o lúdico pode ser utilizado como estratégia de enfrentamento adequado da criança à internação, promovendo seu bem-estar e ampliando suas expectativas quanto ao ambiente hospitalar, o que irá favorecer o trabalho da equipe profissional.

Às vezes, param para ouvir as histórias e riem junto com a criança, porque eles veem o quanto a criança fica bem depois de uma mediação (MF2). A partir do momento que tem a leitura, fica mais fácil de cuidar da criança (...) Faz com que ela aceite melhor o cuidado (MF4). Ás vezes ajuda porque as crianças ficam mais quietas pra eu fazer o meu trabalho, ficam mais calmas (PF8).

A visão lúdica do cuidado reforça a dimensão-saúde da criança para que ela cure a dimensão-doença. ${ }^{10}$ Desta forma, contribui para a reflexão e busca de novas intervenções e estratégias de cuidado, na consideração de que este pode ser uma intervenção direta no corpo, como também valorizar a intersubjetividade da relação, por meio de um gesto, um olhar uma palavra, um toque..$^{11,12}$

0 estabelecimento de nexos da leitura dirigida com as ações de cuidado no campo hospitalar se dá na medida em que esta proporciona um relacionamento de ajuda mútua entre a criança, sua família e a enfermagem, isto é, propicia um cuidado humanizado, em que ambas as partes usufruem dos benefícios desta relação.

Sim, (...) exemplo (...) duas crianças superagitadas e estressadas que não deixavam ninguém chegar perto delas e a mãe não conseguia segurar a criança e seria muito mais traumático para ela ter um grupo de enfermeiras segurando-a. Então, quando os mediadores chegavam e começavama ler os livros, era a hora que conseguíamos fazer alguma coisa nelas, como fazer um curativo, um medicamento, puncionar uma veia. Isso demonstra que com a leitura o comportamento deles mudava (PF3).

À luz destes resultados, pode-se considerar que os mediadores entendem que o cuidado às crianças hospitalizadas 
se expressa pelo carinho e pela atenção que a elas são dirigidas. Entendem que a mediação traz um mundo de fantasia para as crianças internadas, além de ser uma forma de incentivo à leitura, melhorando, assim, suas condiç̃̃es psicológicas. Observando o comportamento positivo das crianças e de seus acompanhantes, eles acreditam que a mediação torna a hospitalização mais aceitável, criando-se uma codependência entre leitura e procedimentos clínicos na prestação dos cuidados à criança.

Referindo-se aos profissionais de enfermagem, os resultados apontam que eles entendem que o cuidado à criança hospitalizada deve ir além das intervenções clínicas, exigindo carinho e atenção. A mediação de leitura é entendida como forma de entretenimento, que interfere positivamente em seu comportamento e, assim, contribui para o tratamento e recuperação. Embora percebam a estreita relação entre leitura e cuidado, esses profissionais veem a mediação como um trabalho independente, ou seja, enquanto a leitura cuida da parte emocional da criança, eles cuidam da parte física. Consideram a mediação como trabalho exclusivo dos voluntários do Projeto Biblioteca Viva, e isso, para eles, é bem delimitado, destacando-se a ideia de que não há condições de se incluir mediação na rotina da assistência de enfermagem, ainda que não tenham apontado de forma clara quais seriam estes impeditivos.

No entanto, a esta consideração dos membros da equipe de enfermagem, cabe uma observação oriunda da pesquisa: a leitura mediada, tomada como um momento de expressão lúdica e descontração para as crianças, acaba por aproximá-las daqueles que promovem as atividades de leitura. Neste sentido, a participação dos membros da equipe contribuiria para a promoção desta aproximação e construção de uma relação mais humana e acolhedora entre eles, o que facilitaria sobremaneira a realização dos cuidados, principalmente os mais invasivos, dolorosos e desconfortantes. Ainda mais, destaca-se que a leitura mediada pode contribuir para que os membros da equipe de enfermagem possam ter um momento de descontração e, assim, usufruir dos benefícios que a atividade lúdica pode lhes trazer no âmbito do trabalho.

\section{CONSIDERAÇÕES FINAIS}

Considerando-se os resultados, entende-se que o ato de cuidar não compreende apenas o tratamento da doença mediante uma intervenção puramente técnica, mas envolve principalmente a interação e trocas entre o cliente e a enfermagem. Portanto, deve-se ter uma visão total do cliente, reconhecendo a sua capacidade de pensar e agir, além de considerar os valores, crenças e a cultura que implicam as suas práticas de cuidado. Neste sentido, o cliente é considerado um ser ativo, sujeito do cuidado, pois humanizar significa observar cada pessoa em sua individualidade, em suas necessidades espećificas, ampliando as possibilidades para que possa exercer sua autonomia. ${ }^{13}$
A partir destes pressupostos, a enfermagem também deve ser entendida como sinônimo de saúde ${ }^{14}$ que se relaciona não só à biologia do corpo como também aos aspectos biopsicossociais. As características do ambiente no entorno do cliente quando hospitalizado, como as cores e os sons, assim como o relaxamento mental e a educação em saúde, são importantes para a promoção do bem-estar e para a prevenção de agravos à saúde.

A expressão lúdica do cuidado de enfermagem vai além da satisfação das necessidades humanas básicas afetadas no cliente, auxiliando na revelação de sentimentos, pensamentos e emoções por meio da fala e expressão corporal do indivíduo, e assim proporciona prazer e equilíbrio, pois emerge na dimensão subjetiva do cuidar, em que a sensibilidade e criatividade são valorizadas. Eainda, o ludismo exerce um efeito terapêutico e também educativo, pois desloca o foco e desmistifica a imagem da hospitalização, tornando a internação mais solidária, humanizada, integrada, alegre e possibilita trocas com a equipe, conseguindo obter uma melhor forma de lidar com a hospitalização.

O ludismo se torna intrínseco no cuidar, estando presente como um todo, na medida em que enfermeiro e cliente são capazes de liberar este componente de sua subjetividade (o lúdico) e, juntos, criar novas maneiras de cuidar a partir da interação, do toque, da atenção, tornando esse cuidado um momento sensível, em que a alegria e o prazer em estar juntos ficam exaltados. Assim, o lúdico, considerado inerente à arte de cuidar, atua sensivelmente na reestruturação da saúde por meio de ações criativas que tornam o cuidado mais prazeroso, trazendo alterações benéficas no estado do cliente que se traduzem na promoção de seu bem-estar. ${ }^{5}$

Os questionamentos perante a complexidade do lidar com o processo saúde-doença são amenizados na dualidade entre a aparente fragilidade do recurso lúdico e a sua forte influência transformadora na hospitalização. A realização de pequenas mudanças abre possibilidades para as transformações mais profundas no âmbito do cuidado, e estas mudanças se relacionam não só à produção de recursos tecnológicos, mas também à valorização de relacionamentos que efetivam a arte do cuidar. ${ }^{15}$

Aplicar o ludismo na concepção e no processo de desenvolvimento do cuidado, especificamente no que se refere à enfermagem, vem ao encontro das reflexões atuais sobre os fundamentos do cuidado e da teoria do cuidado humano em sua vertente expressiva, ${ }^{16-17-18}$ principalmente quando diz respeito ao Projeto Humaniza SUS, ${ }^{1}$ no qual as estratégias de acolhimento, de modo a adequar os serviços ao ambiente e à cultura do cliente, promovendo a ambiência acolhedora e confortável, ganham vulto. 


\section{REFERÊNCIAS}

1. Ministério da Saúde (BR). Secretaria de Atenção à Saúde. Núcleo Técnico da Política Nacional de Humanização. Humaniza SUS: documento base para gestores e trabalhadores do SUS. $3^{\mathrm{a}}$ ed. Brasília(DF); 2006.

2. Almeida MFPV, Figueiredo NMA, Nascimento MAL, Almeida BA. Cuidados para crianças e adolescentes hospitalizados. In: Figueiredo NMA, organizadora. Ensinando a cuidar de criança. São Caetano do Sul(SP): Difusão Paulista de Enfermagem; 2003. p.79-149.

3. Caldin CF. Leitura como função terapêutica: biblioterapia. Encontros Bibli: reflexão em biblioteconomia e ciência da informação [periódico o-line]. 2001 dez. [citado 10 de março de 2008]. 12: [aprox 5 p.] Disponível em: uww.encontros-bibli.ufsc.br/Edicao_12/caldin.html

4. Ferreira MA. As correntes teóricas e práticas das dimensões do cuidar na infância: abordagem introdutória ao tema. Esc Anna Nery Rev Enferm 2002 dez; 6(1): 75-8.

5. Beuter M. Expressões lúdicas no cuidado: elemento para pensar, fazer a arte da enfermagem [tese de doutorado]. Rio de Janeiro (RJ): Escola de Enfermagem Anna Nery/UFRJ; 2004.

6. Geertz C. A interpretação das culturas. Rio de Janeiro(RJ): Livros Técnicos e Científicos; 1989.

7. Bardin L. Análise de conteúdo. 7ªed. Lisboa (PT): Ed 70; 1979.

8. Ministério da Educação (BR). Educação. Brasilia (DF) 2007 [citado 22 jan 2007]. Instituto Puericultura e Pediatria Martagão Gesteira [aproximadamente 6 telas]. Disponível em: http://portal.mec.gov.br/ sesu/arquivos/pdf/humarta.pdf

9. Ribeiro G. Biblioterapia: Uma proposta para adolescentes internados em enfermarias de hospitais públicos. Rev Dig de Biblioteconomia e Ciência da Informação [on-line]. 2006 jan/jun [citado 20 jul 2006].
3(2): [aprox 14 p.] Disponível em: http://server01.bc.unicamp.br/ seer/ojs/include/getdoc.php?id $=265 \&$ article $=45 \&$ mode $=$ pdf

10. Boff L. Saber cuidar: ética do cuidado humano, compaixão pela Terra. Petrópolis (RJ): Vozes; 1999.

11. Ferreira MA, Figueiredo NMA, Arruda A, Alvim NAT. Cuidados fundamentais de enfermagem na ótica do cliente: uma contribuição para a enfermagem fundamental. Esc Anna Nery Rev Enferm 2002 dez; 6(3): 387-96.

12. Mendes P, Castro ES, Ferreira MA. As vertentes do cuidado de enfermagem: o técnico e o expressivo na assistência hospitalar. Esc Anna Nery Rev Enferm 2003 ago; 7(2): 239-46.

13. Fortes PAC, Martins CL A ética, a humanização e a saúde da família. Rev Bras Enferm [periódico on-line] 2002 mar/abr [citado 25 jul 2007]. 55(2):[aprox 6 p ] Disponível em: www.scielo.com.

14. Nightingale F. Notas sobre enfermagem: o que é e o que não é. São Paulo(SP): Cortez; 1989.

15. Kumamoto LHMCC, Gadelha ECM, Monteiro FR, Silva LRMS, Leite MC, Santos RGC. Apoio à criança hospitalizada: uma proposta de intervenção lúdica. Rev Eletr Extensão Cidadã [periódico on-line]. 2006. [citado 18 abr 2008]. 1: [aprox 12 p.] Disponível em: http:// unw.ies.ufpb.br/ojs2/index.php/extensaocidada/article/view/1340.

16. Watson J. Enfermagem: ciência humana e cuidar: uma teoria de enfermagem. Lisboa (PT): Lusociência, 2002. Edições Técnicas e Científicas.

17. Talento B. Jean Watson. In: George JB, organizadora. Teorias de enfermagem: os fundamentos para a prática profissional. Porto Alegre (RS): Artes Médicas; 1993. p. 254-67.

18. Ferreira MA. 0 corpo no cuidado de enfermagem: representações de clientes hospitalizados. [tese de doutorado]. Rio de Janeiro (RJ): Escola de Enfermagem Anna Nery/UFRJ; 1999. 